Images dans le monde ibérique et ibéricoaméricain

$6 \mid 2013$

Images dans le monde ibérique et ibéro-américain

Democracia intercultural y representación políticaen las autonomías departamentales e indígenas

\title{
Fernando Mayorga
}

\section{(2) OpenEdition}

Journals

Edición electrónica

URL: https://journals.openedition.org/agedor/771

DOI: $10.4000 /$ agedor.771

ISSN: 2104-3353

Editor

Laboratoire LISAA

Referencia electrónica

Fernando Mayorga, «Democracia intercultural y representación políticaen las autonomías departamentales e indígenas», L'Âge d'or [En línea], 6 | 2013, Publicado el 01 marzo 2013, consultado el 21 septiembre 2021. URL: http://journals.openedition.org/agedor/771 ; DOI: https://doi.org/10.4000/ agedor.771 
Fernando MAYORGA

Universidad Mayor San Simón de Cochabamba, CESU.

\title{
DEMOCRACIA INTERCULTURAL Y REPRESENTACIÓN POLÍTICA EN LAS AUTONOMÍAS DEPARTAMENTALES E INDÍGENAS
}

\begin{abstract}
Résumé : Il s'agit d'analyser l'état d'avancement de la construction institutionnelle de la démocratie interculturelle en prêtant attention aux critères et aux règles de la représentation politique qui ont été intégrés aux statuts d'autonomies départementales et aux statuts des autonomies indigènes. Il s'agit également d'évaluer, dans la mesure du possible, les conceptions de la démocratie interculturelle dans d'autres contextes comme, par exemple, dans le cadre de projet de Loi de consultation préalable et de la Loi des organisations politiques. Cependant nous limitons notre analyse à la représentation politique parce que c'est précisément là où nous trouvons le plus grand nombre d'éléments pour évaluer le processus institutionnel de la démocratie interculturelle.
\end{abstract}

Mots-clés : démocratie - interculturalité - autonomies indigènes - représentation politique Bolivie

Resumen: En este texto analizamos los avances en la construcción institucional de la democracia intercultural prestando atención a los criterios y a las reglas referidas a la representación política que se incorporaron en los estatutos autonómicos departamentales y en los estatutos indígenas. También es posible evaluar las perspectivas de la democracia intercultural en otros tópicos, como el anteproyecto de Ley de Consulta Previa y de la Ley de Organizaciones Políticas, no obstante circunscribimos nuestro análisis a la representación política porque en este tópico existen más elementos para evaluar el proceso de construcción institucional de la democracia intercultural.

Palabras clave: democracia - interculturalidad - autonomías indígenas - representación política Bolivia

$\mathbf{E}$ s necesario establecer algunos criterios conceptuales y metodológicos como punto de partida del análisis puesto que no existen pautas convencionales para definir de manera precisa los alcances del uso de la noción de democracia intercultural. Por lo pronto, el andamiaje institucional de la democracia intercultural que se va forjando en diversos ámbitos políticos, sobre todo subnacionales, proporciona elementos para una intelección acerca de la naturaleza y las características de este modelo de democracia. 
El término democracia intercultural remite, obviamente, a un lazo entre lo democrático y lo intercultural. Por ese motivo existe la tendencia a enfatizar algunos aspectos de ese lazo, como aquel que se refiere a la presencia de representantes indígenas y a la incorporación formal de normas y procedimientos de las naciones y pueblos indígenas originario campesinos en el sistema político. Es decir, la democracia intercultural sería tal en la medida que se incorporan elementos de la democracia comunitaria en el (re)diseño institucional de los órganos de gobierno. No obstante, considero que es un desacierto circunscribir el análisis de la construcción de la democracia intercultural a los avances en democracia comunitaria para la elección de autoridades y representantes y para la definición del proceso político decisional.

Esta constatación no pierde de vista el hecho de que el reconocimiento de la democracia comunitaria es un aspecto central del modelo boliviano de democracia, que determina su especificidad y originalidad. El modelo político boliviano es el único diseño institucional en el cual la democracia comunitaria se aúna a la democracia representativa y a la democracia participativa. En varios países del continente, sobre todo en Venezuela y Ecuador, se incorporaron instituciones de democracia directa e, inclusive, sus modelos políticos se denominaron con los términos de "democracia protagónica", en el caso venezolano, y de "revolución ciudadana", en el caso ecuatoriano, para enfatizar la faceta participacionista de la democracia. Se trata de procesos de ampliación de la democracia similares al caso boliviano, empero se limitan a la combinación de instituciones de democracia representativa y participativa o directa. Sin duda, la centralidad del movimiento indígena y campesino en el proceso constituyente boliviano es el factor explicativo del sello peculiar de los cambios constitucionales en nuestro país que se tradujeron en la creación del Estado Plurinacional y, además, se expresó en el reconocimiento de un sujeto portador de derechos colectivos -naciones y pueblos indígena originario campesinos-, con consecuencias en el (re)diseño de las instituciones políticas

Con todo, la democracia intercultural no es una estructura o modelo establecido normativamente en sus diversos aspectos, puesto que sus contornos no están definidos en la Constitución Política, tampoco en las leyes y, por ese motivo, resulta más pertinente considerar a la democracia intercultural como un proceso y una relación.

Antes de esbozar esta caracterización es necesario mencionar que el vocablo democracia intercultural ha aparecido, hace poco, de manera específica en la Ley de Régimen Electoral donde se plantea que el objeto de esta norma es: "regula[r] el Régimen Electoral para el ejercicio de la Democracia Intercultural" (Art 1. Ley de Régimen Electoral).

En esta norma se presenta a la democracia intercultural de la siguiente manera: "la democracia intercultural del Estado Plurinacional de Bolivia se sustenta en el ejercicio complementario y en igualdad de condiciones de tres formas de democracia: directa y participativa, representativa y comunitaria, en el marco de lo dispuesto por la Constitución Política y las Leyes en materia electoral" (Art.7. Ley de Régimen Electoral, cursivas mías). Es decir, ese adjetivo pretende definir normativamente el carácter específico de la democracia boliviana aunque, a nuestro juicio, se trata simplemente de una caracterización; no es una definición. No dice qué es la democracia intercultural sino cuáles son sus componentes, y el tipo ideal de relaciones entre esos componentes, es decir, un ejercicio complementario en igualdad de condiciones. 
De acuerdo a la Constitución Política, los componentes institucionales de las tres formas de democracia son las siguientes. En la democracia directa y participativa: referendo, iniciativa legislativa ciudadana, revocatoria de mandato, asamblea, cabildo y consulta previa. En la democracia representativa: voto universal, directo y secreto para la elección de representantes. En la democracia comunitaria: normas y procedimientos propios de las naciones y pueblos indígena originario campesinos para la elección, designación o nominación de autoridades y representantes.

Entonces, para reafirmar la idea de que la democracia intercultural debe ser entendida como una relación y un proceso es plausible señalar que la democracia intercultural no se refiere a un determinado objeto institucional sino que comprende diversas reglas y prácticas; tampoco convoca a un sujeto específico puesto que en su apelación discursiva interpela a múltiples actores sociales: ciudadanos, pueblos, comunidades. Por esa razón insistimos en que se trata de un proceso y una relación ${ }^{1}$.

En primer lugar, la democracia intercultural es un proceso porque los vínculos entre las formas de democracia se ampliarán y complejizarán a medida que se vayan consolidando las nuevas entidades estatales, sobre todo los gobiernos departamentales y las autonomías indígenas. En la medida en que en esos ámbitos subnacionales se cristalicen institucionalmente diversas modalidades de vínculo entre democracia representativa, participativa y comunitaria dispondremos de elementos para juzgar la eficacia y la legitimidad de las reglas para la elección y desempeño de las autoridades y representantes políticos. En ese sentido, la democracia intercultural es un proceso incremental de ajuste e innovación institucional que se renueva de manera constante a partir de la evaluación de sus costos y resultados políticos.

En segundo lugar, la democracia intercultural es una relación porque se expresa en un conjunto de interacciones que varían en el tiempo y espacio. Las interacciones entre las formas de democracia son asincrónicas porque se combinan de manera disímil y variable dependiendo del escenario político e institucional en cuestión. La combinación de reglas de las distintas formas de democracia debe propiciar la articulación de la diversidad social que se quiere representar, empero también debe evitar que se produzcan situaciones de crisis política. En suma, se trata de plantear distintas maneras de articulación transformadora entre democracia representativa, participativa y comunitaria a partir de un ejercicio complementario y en igualdad de condiciones evitando que su resultado provoque dualismo en el sistema de representación política y en el proceso decisional. La pretensión de "articulación transformadora" está esbozada en los principios de la Ley de Régimen Electoral, uno de los cuales se refiere a la "complementariedad": La democracia intercultural boliviana se fundamenta en la articulación transformadora de la democracia directa y participativa... la democracia representativa... y la democracia comunitaria (Art. 2, inciso d).

Si bien el ejercicio de estas instituciones puede ser complementario es evidente que siempre será parcial, puesto que implica un nexo particular entre algunas instituciones de las tres formas de democracia, dependiendo de la arista del proceso político y/ del locus institucional del proceso político. Asimismo, aunque se presupone la igualdad de condiciones entre las tres formas de democracia, en cualquier diseño institucional específico se

${ }^{1} \mathrm{Al}$ respecto, "Democracia intercultural y organizaciones políticas" en Andamios, Boletín de Análisis y Prospectiva Política, PNUD, La Paz, 2012. 
producirá, de manera inevitable, el predominio de una institución o regla democrática sobre otra(s) en función de los objetivos del diseño institucional en cuestión, ya sea respecto al equilibrio del sistema político, o bien si se otorga énfasis a aspectos de representación política o de participación ciudadana.

Para concluir con esta reflexión introductoria es necesario destacar que la comprensión y definición de la democracia comunitaria se enriquece de manera paulatina. Primero a través de las leyes y, luego -como veremos- con los estatutos indígenas. En el texto constitucional la democracia comunitaria se refiere específicamente a la "elección, designación o nominación de autoridades y representantes" mediante "normas y procedimientos propios de las naciones y pueblos indígena originario campesinos" (Art. 5). Es decir, en la Constitución Política, la democracia comunitaria, al igual que la democracia representativa, se refiere a la representación política; la diferencia radica en la incorporación formal de diversas modalidades de elección en las comunidades indígenas que no se ajustan al voto universal, individual, de corte liberal. Posteriormente la definición de la democracia comunitaria fue enriquecida en la Ley de Régimen Electoral respecto a la caracterización constitucional que la circunscribía a la "elección, designación o nominación de autoridades y representantes". Esa norma electoral establece que la democracia comunitaria "se ejerce mediante el autogobierno, la deliberación, la representación cualitativa y el ejercicio de derechos colectivos, según normas y procedimientos propios de las naciones y pueblos indígena originario campesinos" (Art. 10, Ley de Régimen Electoral). La inclusión de autogobierno se refiere a las autonomías indígenas, la representación cualitativa tiene que ver con los escaños en las asambleas legislativas y el ejercicio de derechos colectivos tiene relación con la consulta previa que es la única institución (de democracia directa y participativa) que es mencionada de manera expresa como derecho colectivo. Es decir, la Ley de Régimen Electoral amplia la democracia comunitaria y sus efectos institucionales. Precisamente, estos son los tópicos que analizamos a continuación prestando atención a las diversas modalidades de articulación o disyunción entre reglas y procedimientos de las formas de democracia enfocando nuestro análisis en la representación política.

\section{Democracia(s) y representación política}

La implementación de la democracia intercultural se inició en los comicios generales de diciembre de 2009 y en las elecciones subnacionales de abril de 2010. Para el ámbito nacional se definió, en la Ley de Régimen Electoral Transitorio, la incorporación de diputados de las naciones y pueblos indígena originario campesinos "minoritarios" en la Asamblea Legislativa Plurinacional mediante su elección en circunscripciones especiales, sin el requisito de continuidad territorial. No obstante las reglas de su elección fueron similares a las de los diputados uninominales, es decir se eligieron mediante competencia electoral a través del voto individual, libre y directo, y los candidatos fueron postulados por organizaciones políticas, esto es, partidos políticos y agrupaciones ciudadanas. Es decir, las circunscripciones especiales se definieron por criterios identitarios que prestaban atención a la diversidad étnica, no obstante el procedimiento de elección fue uniforme mediante el voto universal como mecanismo convencional de la democracia representativa.

En 2009 se eligieron 7 diputados indígenas, uno por cada departamento, excepto Potosí y Chuquisaca. Para los comicios a realizarse en el segundo semestre de 2014 no se realizarán modificaciones en el porcentaje de diputados indígenas (5\% de 130 representantes en la cámara baja) puesto que el Órgano Electoral Plurinacional propuso una redistribución de 
escaños a partir de los datos del último Censo Nacional de Población y sus decisiones no afectaron la cantidad de diputados establecidos en la norma anterior. En la "Propuesta del Tribunal Supremo Electoral para la distribución del total de escaños entre los nueve departamentos de Bolivia" se mencionan diversos criterios para definir la asignación de escaños, entre ellos los de equidad y proporcionalidad con relación a los departamentos con menor población y con menor desarrollo económico, asimismo se establece una relación porcentual más equitativa entre diputados plurinominales y uninominales. Empero respecto a los curules de las circunscripciones especiales simplemente se ratificó la cifra anterior, pese a las demandas de las organizaciones indígenas y a las promesas del partido de gobierno para incrementar el número de diputados indígenas. En este acápite no abordamos el análisis de las causas de esta decisión, simplemente constatamos la ratificación de una regla que incorpora parcialmente la democracia comunitaria en el órgano nacional de representación política. En este caso, esa regla reduce los riesgos de una situación de dualismo representativo puesto que a la razonable cantidad de diputados indígenas se suma su postulación mediante organizaciones políticas y su elección mediante procedimientos de democracia liberal. Es decir, la democracia comunitaria se articula a la democracia representativa de manera subordinada puesto que las formas de elección y los grados de autonomía de los representantes (en cuanto principios de la representación política $^{2}$ ) están bajo la influencia de las mediaciones partidistas y no de las comunidades $\mathrm{u}$ organizaciones indígenas puesto que al no ser elegidas por normas y procedimientos propios no existen posibilidades de que se sometan a criterios de mandato imperativo de sus electores.

Este tema no es banal puesto que la autonomía de acción de los diputados uninominales, en general, se refiere a la incidencia de su conciencia o criterio personal, o bien de las directrices partidistas o, finalmente, de las presiones de sus mandantes para la adopción de sus decisiones. En el caso particular de los diputados indígenas debe sumarse la influencia de las organizaciones sociales a las que pertenecen y, también, representan. Un ejemplo puede ilustrar la complejidad de estas relaciones: el intento de formación de una "bancada indígena" para representar los intereses del movimiento indígena frente al gobierno del MAS y, por ende, a la bancada oficialista en torno al conflicto por el TIPNIS. Este intento fue efímero porque seis de los siete diputados indígenas fueron postulados por el MAS y formaban parte de la bancada oficialista. Ante la disyuntiva de actuar a favor o en contra de las directrices del MAS terminaron desechando la idea de organizar una bancada que siga las directrices de una organización nacional indígena como CIDOB. Entre los argumentos adicionales de este desistimiento surgieron aspectos de carácter reglamentarios, como la posibilidad de pérdida de curul por transfugio político o el hecho de que el Reglamento General de la Cámara de Diputados no reconoce la existencia de bancadas dentro de una misma fuerza política. Este evento expone las dificultades de la articulación de democracia representativa y comunitaria en la representación política si el ámbito de concreción es una organización política o un partido. Estos problemas son menores cuando se trata de espacios de política institucional en el nivel subnacional, como las autonomías departamentales e indígenas.

\section{Asambleas departamentales: ampliación de la representación política}

\footnotetext{
${ }^{2} \mathrm{Al}$ respecto, Bernard Manin, Los principios del gobierno representativo, Alianza editorial, Madrid, 1997.
} 
Un espacio político donde se materializa institucionalmente la democracia intercultural es aquel ámbito prefigurado por las autonomías departamentales. La primera elección de asambleístas departamentales se produjo en abril de 2010 bajo las pautas establecidas en la Ley Transitoria de Régimen Electoral. En esa ocasión se eligieron representantes de pueblos indígenas en ocho de los nueve departamentos con diversos porcentajes. En el caso de Potosí no se aplicaron reglas de democracia comunitaria bajo el criterio de que no existen pueblos indígenas "minoritarios" y la elección del total de asambleístas departamentales se realizó mediante voto universal y con mediación partidista. En el departamento de Beni se eligieron 4 de 28 asambleístas, en el caso de Santa Cruz se eligieron 5 de 28, en Oruro 1 de 33, en Chuquisaca 2 de 21, en Tarija 3 de 30, en La Paz 5 de 45, en Cochabamba 2 de 34 y en Pando 1 de 16.

En las elecciones departamentales de 2010 se produjeron situaciones más evidentes de democracia intercultural porque se combinaron procedimientos de democracia representativa, como el voto universal para los asambleístas en general, y de democracia comunitaria, para el caso de los asambleístas indígenas, elegidos mediante normas y procedimientos propios en todos los casos. Sin embargo, se trata de una combinación de instituciones, sin articulación. A diferencia de los diputados, los asambleístas indígenas son elegidos directamente por sus comunidades o pueblos con base en sus reglas y sin competencia electoral, es decir no se produce una amalgama de reglas, y las organizaciones políticas no intervienen en la elección de los representantes indígenas. Ahora bien, ¿existen modificaciones a este diseño institucional en los estatutos autonómicos departamentales?

El diseño institucional de las autonomías departamentales mediante la elaboración de estatutos es una tarea que avanza lentamente. A fines de este año, este proceso muestra como resultado la aprobación de solamente un estatuto por parte del Tribunal Constitucional Plurinacional y está pendiente la revisión de cuatro proyectos de estatutos aprobados por las asambleas departamentales. En algunos casos existen novedades en el diseño de los sistemas de gobierno con la adopción de diversas instituciones de las tres formas de democracia, con un relativo énfasis en la democracia comunitaria.

El Estatuto Autonómico de Pando registra un incremento de 16 a 21 en el número de curules y, en el caso de los representantes indígenas la cifra se incrementa (de uno) a tres. De manera específica, se establece la elección de 21 asambleístas: 15 por territorio (uno por municipio), 3 por población (dos para el municipio más poblado y uno para el segundo) y, finalmente, 3 escaños para los pueblos indígena originario campesinos de minoría poblacional, que corresponden a cinco pueblos: Tacana, Cavineño, Esse Ejja, Machineri y Yaminahua (Artículo 37 del título III). Es importante mencionar que se deja abierta la posibilidad de un incremento hasta un número de cinco asambleístas indígenas. Se define su elección mediante normas y procedimientos propios, no obstante se especifica que la elección debe respetar la equidad de género.

Un diseño opuesto presenta el Estatuto Departamental de Cochabamba en la medida en que no se presentan modificaciones a la composición de la Asamblea Legislativa Departamental definida por la Ley Transitoria del Régimen Electoral de 2010. Se mantienen 2 asambleístas indígenas de un total de 34, los que son elegidos por criterios de representación territorial (provincial) y poblacional. El par de asambleístas corresponden a pueblos indígenas minoritarios y se eligen por normas y procedimientos propios. 
Un panorama similar presenta el caso del departamento de Tarija porque no se presentan modificaciones en el tamaño ni en la distribución de la Asamblea Legislativa Departamental. Ratifica su composición con 30 representantes, de los cuales 12 son elegidos con base en el principio de igualdad territorial de las provincias y 15 por población, mediante sufragio universal. Los tres restantes son representantes de los pueblos indígena originario campesinos, los cuales son nominados -al igual que en el caso de Pando- y corresponden a los pueblos: Guaraní, Weenhayek y Tapiete. En este caso se utiliza la noción de usos y costumbres para designar las reglas de su elección. Aunque se menciona que, en general, debe garantizarse "el criterio de alternancia y paridad entre mujeres y hombres en la presentación de listas electorales", no se menciona si este principio debe ser asumido de manera específica por los pueblos indígenas, y en la medida que en estos casos no existen listas electorales es dable suponer que no se puede aplicar dicho criterio. Vale la pena resaltar que el Estatuto explicita el reconocimiento constitucional de la democracia directa, representativa y comunitaria, no obstante las define como "formas de participación democrática" (Art. 42).

En el caso de departamento de Potosí, el Anteproyecto de Estatuto establece la incorporación de un representante indígena a la Asamblea Legislativa Departamental. Así, de un total de 33 asambleístas se incluye "una o un Asambleísta, que represente a todos los Pueblos Indígena Originario Campesinos minoritarios existentes en el Departamento" (Art. 15). No se define una modalidad específica de su elección, tampoco existe la mención a las normas y procedimientos propios ni se denomina a los pueblos indígenas. La regla de elección es general y se refiere que se realizará "mediante voto directo universal y secreto, por las y los ciudadanos, en listas separadas de las candidatas o candidatos a Gobernadora o Gobernador" (Art. 18). Posiblemente ese tópico relativo a la democracia comunitaria se defina en el régimen electoral departamental, aunque no se señala de manera explícita como acontece en los restantes casos- que se aprobará una Ley Electoral específica. Un elemento distintivo en este Estatuto es la definición de la Participación social (Art. 37) donde se destaca la "participación directa" en iniciativa legislativa ciudadana, referendo y consulta previa departamental. Es decir, de manera similar al Estatuto de Tarija, las formas de democracia son entendidas como formas de participación.

Finalmente, en el caso de La Paz, el proyecto de Estatuto define que adopta para su gobierno cuatro -no tres- formas de democracia: autonómica, participativa, representativa y comunitaria Art. 8). La primera modalidad no es definida pero puede colegirse que pretende referirse a la descentralización intra departamental. Se ratifica la composición de la Asamblea Legislativa Departamental con 45 representantes de los cuales 5 son asambleístas que representan a las naciones y pueblos indígena originario y campesinos. No se explicitan las modalidades de su elección para ningún caso, simplemente remite a los artículos constitucionales que definen las pautas generales de acceso a cargos públicos. En la medida que se prevé la elaboración de una Ley Electoral Departamental se supone que en esa norma se definirán las reglas respecto a la representación política.

En suma, en la elaboración de estatutos departamentales se han ratificado a grosso modo los criterios establecidos en la Ley Transitoria de Régimen Electoral respecto a la composición de las Asambleas Departamentales, en especial a la presencia de representantes de los pueblos indígenas. Se ha incrementado el número de asambleístas indígenas en el caso de Pando y Potosí, no se especifican modalidades de elección en dos casos (Potosí y La Paz) y se utilizan términos similares para designar a las reglas de la 
democracia comunitaria: usos y costumbres, en el caso de Tarija; normas y procedimientos propios, en los demás. En algunos casos se confunden formas de democracia con formas de participación, en otro caso se incluye la "forma autonómica" de democracia sin definirla. Un elemento que implica un grado de uniformidad en la diversidad de modalidades de elección es la aceptación del principio de alternancia y equidad de género.

Un balance general muestra que la representatividad de las asambleas departamentales como órganos de la democracia representativa se amplía con la presencia de representantes elegidos mediante pautas de democracia comunitaria. La ampliación de la democracia tiene que ver no solamente con la adopción de reglas que incorporen a sectores de la sociedad por criterios generacionales y de género, sino que incluyan grupos sociales a partir de aspectos identitarios y culturales. Ahora bien, un tema pendiente de análisis de las conducta políticas en estos órganos legislativos es la relación discursiva entre representantes elegidos con distintas lógicas o procedimientos, es decir, si la diferencia de la legitimidad de origen tiene consecuencias positivas o negativas para el desempeño de los asambleístas, y en particular si se produce una deliberación democrática a partir de esa diferencia en las modalidades de elección que implica una distinción en el lazo representativo de los asambleístas departamentales.

\section{Estatutos indígenas: la levedad de las fronteras entre representación y participación}

A diferencia del nivel departamental, en las autonomías indígenas no existen antecedentes para realizar una mirada comparativa para evaluar los avances en la democracia intercultural. Se trata de nuevos diseños institucionales de órganos de (auto)gobierno que implica una formalización de reglas y prácticas consuetudinarias que, en el pasado, convivían de múltiples maneras con las normas legales. La Ley de Participación Popular fue un intento de articulación de elementos de democracia comunitaria (aunque no se la definía de esa manera) con la democracia representativa en el nivel municipal, empero las experiencias estuvieron basadas en una subordinación de la democracia comunitaria a la democracia representativa. Esa adecuación subordinada tenía muchos costes negativos para los actores políticos y sociales puesto que debían resolver las candidaturas internamente para, posteriormente, formalizarlas en una lista partidista. Precisamente, la transformación del modelo estatal respondió en cierta medida a las demandas del movimiento indígena que inicialmente planteó una propuesta de autonomías circunscrita a las autonomías indígenas bajo el criterio de autodeterminación como base del Estado Plurinacional ${ }^{3}$. El proceso constituyente concluyó con un modelo de Estado compuesto que reconoce cuatro tipos de autonomía: departamental, municipal, indígena y regional. Esta es una de las razones para caracterizar el proceso de edificación del Estado Plurinacional como una construcción minimalista que, en este caso, muestra rasgos adicionales de una reforma de carácter incremental, de tipo gradual. ${ }^{4}$

Las autonomías indígenas son el espacio político para la vigencia de la democracia comunitaria. Su materialización institucional es parsimoniosa y sigue dos rutas: referendo para convertir un municipio en autonomía indígena y trámite para el reconocimiento de Territorios Indígena Originario Campesinos en autonomías indígenas. La primera

\footnotetext{
$3 \mathrm{Al}$ respecto, Fernando Garcés, sistematizador, El Pacto de Unidad y el proceso de construcción de una propuesta de Constitución Política del Estado, Preview Gráfica, La Paz, 2010.

$4 \mathrm{Al}$ respecto, Fernando Mayorga, Dilemas. Ensayos sobre democracia intercultural y Estado Plurinacional, Plural editores, La Paz, 2012.
} 
modalidad tiene once casos de conversión de municipios en autonomías indígenas, no obstante existen solamente cinco experiencias de diseño institucional hasta la fecha, las que son analizadas en este trabajo. La segunda vía también presenta una cifra similar de casos aunque con ritmos diversos: certificación de "Viabilidad Gubernativa" a Raqaypampa en Cochabamba, certificación de "Territorio Ancestral" a Monte Verde en Santa Cruz, Camata en La Paz y Territorio Indígena Multiétnico en Beni; y se encuentran en proceso de evaluación las solicitudes del Consejo Indígena Yuracaré y Jatun Ayllu Kirkiawi en Cochabamba, Lomerío en Santa Cruz y Jatun Ayllu Yura en Potosí. ${ }^{5}$

Respecto a la modalidad de conversión mediante referendos, en diciembre de 2009 se realizaron consultas electorales para la transformación de 12 municipios en autonomías indígenas: Chipaya, Pampa Aullagas, Totora, Curahuara de Carangas y Salinas de Garci Mendoza en el departamento de Oruro; Huacaya, Tarabuco y Villa Mojocoya en Chuquisaca; Charazani y Jesús de Machaca en La Paz; Charagua en el departamento de Santa Cruz y Chayanta en Potosí.

De esa docena de municipios, once obtuvieron los votos necesarios para su conversión a autonomía indígena. Se trata del 3\% de los 337 municipios existentes en el país. Esta cifra adquiere otra dimensión cuando se considera su tamaño puesto que los municipios que lograron su conversión a autonomía indígena suman el 8,2\% del territorio nacional. Entre esos municipios se encuentra el más grande del país - Charagua-, que corresponde casi al 30\% del departamento de Santa Cruz. La superficie que ocupan las cuatro autonomías indígenas de Oruro bordea el 17\% del territorio de Oruro y, en el caso de Chuquisaca, las tres autonomías indígenas corresponden al $7 \%$ del territorio departamental. Los restantes casos son menores en extensión territorial ${ }^{6}$. En las elecciones municipales de 2010, el MAS venció en nueve municipios ; en Charagua venció VERDES y el MSM en Huacaya.

A fines de 2103 solamente un caso de autonomía indígena -Totora Marka- concluyó su trámite de aprobación de Estatuto con fallo favorable del Tribunal Constitucional Plurinacional. Cuatro casos están pendientes de culminar la fase de revisión constitucional: Pampa Aullagas, Charagua, Mojocoya y Uru Chipaya.

Para evaluar los avances en democracia intercultural en el ámbito de las autonomías indígenas evaluamos los rasgos generales que presentan los sistemas de gobierno y las reglas de elección de autoridades y representantes, en particular las disyunciones o superposiciones entre reglas de democracia representativa y democracia comunitaria.

En cuatro de los cinco casos de estudio se plantean tres niveles o instancias de gobierno: deliberativa, legislativa y ejecutiva. El órgano principal de poder político es la instancia deliberativa porque se constituye en la máxima autoridad a la cual se subordinan los órganos de gobierno convencionales: legislativo y ejecutivo. Existen diferencias en cuanto a su composición y su organización puesto que, en un par de casos, se divide verticalmente en varios niveles de participación social.

\footnotetext{
$5 \mathrm{Al}$ respecto, "Estado del proceso de construcción de autonomías indígena originario campesinas en el Estado Plurinacional de Bolivia”, Ministerio de Autonomías, noviembre de 2013, http://es.slideshare.net/MinAutonomia/del-proceso-de-construccin-de-autonomas-indgena-originario2 ${ }^{6} \mathrm{Al}$ respecto, Autonomías indígenas, un proceso a construir, FAM Bolivia, La Paz, 2010.
} 
En el caso de Totora Marka de la Nación Originaria Suyu Jach'a Karangas esa instancia deliberativa se denomina Consejo de Autoridades Originarias (J'acha Mara Tantachawi) y está conformada por autoridades originarias que acceden a esos cargos por rotación y por autoridades de cada ayllu, delegados territoriales -32 guías y 32 corregidores-, y representante de sectores y organizaciones sociales. Este Consejo se define como "la máxima instancia de participación, cuyas decisiones son vinculantes para todas las instancias de gobierno" (Art. 75). Si bien se establece que sus facultades son la deliberación, consulta, fiscalización, evaluación y control social, también se presenta como "instancia de participación y decisión" denotando la concentración de funciones en esa instancia que, entre otras atribuciones, está facultada para la "revocatoria de mandato de todas las autoridades electas". (Art. 77). El órgano legislativo está conformado por representantes de los ayllus con equidad expresada en paridad y alternancia de género, de acuerdo a normas propias de la Marka" (Art. 8, inciso a). Vale resaltar que entre los representantes elegidos para la instancia deliberativa se designa tanto al ejecutivo (Jiliri irpiri) como al presidente del órgano legislativo (Art. 80, inciso b). El caso de Totora Marka es un ejemplo de adopción de un sistema de gobierno basado en la democracia comunitaria, tal como se define en el Artículo 73: "Asume como forma de gobierno el modelo del ayllu, sobre la base del ejercicio del derecho a la libre determinación, autogobierno, expresada en la democracia comunitaria originaria dual, directa, participativa, muyu (rotación de cargos por ayllus), sara thaqi, que se manifiesta de acuerdo a normas, mecanismos y procedimientos propios".

En el caso del Estatuto del Gobierno Autónomo de la Nación Originaria Uru Chipaya también se reconocen tres órganos de gobierno y la instancia deliberativa (Chawkh Parla) es definida como la "máxima instancia de ejercicio de la democracia comunitaria, de decisión y deliberación" del gobierno (Art. 27). Su composición contempla a las autoridades originarias (Repth retalla mayores) de los cuatro ayllus como "dirección" de esta instancia deliberativa, pero también involucra a autoridades "políticas, instituciones públicas y comunitarias" denotando una amplia lógica participacionista. Esta instancia deliberativa designa a la máxima autoridad de la nación originaria y a la autoridad ejecutiva por rotación de los ayllus. En el caso del órgano legislativo se establece una conformación con base en dos representantes por ayllu, uno de carácter territorial, elegido según normas y procedimientos propios; otro representa a las autoridades comunitarias (Rep ret'alla segunda). En el caso del órgano ejecutivo (alcalde), el ayllu que, por rotación, se hace cargo de su conducción presenta una terna de candidatos que formulan sus planes de gobierno y uno es designado como autoridad por la máxima instancia deliberativa. Las ternas proporcionadas por cada ayllu también se utilizan para seleccionar a los candidatos a diputados, senadores, asambleístas departamentales, gobernador y otros cargos electivos (Art. 30, inciso g), aunque no se precisa el uso de la regla de rotación entre representantes de ayllus, regla que marca las pautas de funcionamiento de la democracia comunitaria en Uru Chipaya.

En el caso del Estatuto de la Marka Pampa Aullagas se establecen igualmente las tres instancias: deliberativa, legislativa y ejecutiva. La máxima instancia (J'acha Tantachawi) tiene carácter decisorio y vinculante sobre las otras instancias de gobierno y contempla la participación de "todas las aullagueñas y todos los aullagueños y por la estructura de autoridades originarias, sociales y políticas de las comunidades, ayllus y la Marka" (Art. 14), sin embargo se ordena verticalmente en tres espacios de participación: cabildo mensual, cabildo extraordinario y cabildo de ayllu. Es una estructura territorializada del proceso deliberativo con una combinación de asambleas que tienen una composición variable y que 
se erigen de "abajo hacia arriba". El órgano legislativo está conformado por cinco miembros (Ulaqa Unanchiri) que son elegidos por normas y procedimientos propios, acontece de manera similar con la autoridad ejecutiva (Kamachi Phuqhayiri). En las normas y procedimientos propios se definen pautas precisas puesto que "La modalidad de elección para el Unanchiri y Kamachi Phuqhayiri y sus suplentes consiste en: a) Ser elegida o elegido por Q'allta (primer paso para ejercicio de autoridad comunal) un año antes de ejercer el cargo en el Ayllu Tantachawi al que corresponde; b) Entre los elegidos de los ayllus de la Marka, conforme al muyu (rotación cíclica), se designará al (ejecutivo) Kamachi Phuqhayiri y a los integrantes del (legislativo) Ulaqa Unanchiri; c) El cargo (ejecutivo) Kamachi Phuqhayiri es de carácter rotativo entre los ayllus, respetando la equidad de género (Art. 39).

En el Estatuto del Gobierno Autónomo Guaraní Charagua Yyambae también se introducen varios niveles de consulta y deliberación en la máxima instancia de gobierno porque esta está conformada por tres asambleas "en orden ascendente": comunal, zonal y autonómica. En este caso, la máxima autoridad (Nemboati Reta) no se define como instancia deliberativa sino como Órgano de Decisión Colectiva, cuyas resoluciones son de "observancia obligatoria" para los otros órganos de gobierno. Esas instancias intermedias son las que proponen candidatos para el órgano legislativo y el órgano ejecutivo. El Órgano Legislativo (Mborokuai Simbika Iyapoa) está compuesto por 12 legisladoras y legisladores (dos por Zona) elegidos según criterios de equidad de género por un periodo de mandato de 5 años y por una sola vez. Su postulación y elección es de acuerdo a normas y procedimientos propios. Para el caso del Tëtarembiokuai Reta (Órgano Ejecutivo) se plantea una composición de 6 ejecutivas/os, uno por cada Zona, y el Tëtarembiokuai Reta Imborika (Alcalde) con funciones específicas que asume el cargo mediante rotación entre representantes de Zonas por un período de tres años.

Finalmente, el proyecto de Estatuto de Mojocoya presenta rasgos disímiles a los cuatro anteriores porque establece los dos órganos de gobierno convencionales y no establece una instancia comunal con mayor autoridad. A lo sumo se proclama que la selección de candidatos, "en el marco del ejercicio de la democracia comunitaria" se realizará "desde el nivel de la comunidad, centros poblados y zonales" por normas y procedimientos propios (Art. 23, I). Sin embargo, la Asamblea Legislativa se conforma mediante voto universal libre y secreto con los cinco candidatos más votados de los ocho candidatos propuestos por ampliados zonales -conformados por representantes de comunidades y por las comunidades y centros poblados. Esta regla también se adopta para el cargo ejecutivo, denominado Autoridad Mayor (Jatun Kamachi), porque accede a ese cargo ejecutivo el candidato más votado de los cuatro propuestos por los mismos niveles de consulta: centros poblados, comunidades y ampliados zonales. Es decir, se utilizan reglas de la democracia comunitaria para postular candidatos y se los elige mediante reglas de la democracia representativa.

\section{Perspectivas y desafíos}

La democracia intercultural se encuentra en un proceso de construcción gradual que contempla, en el caso de las autonomías departamentales, la combinación de reglas de democracia comunitaria y democracia representativa con predominio de esta última modalidad que ordena el proceso electoral y el proceso político decisional. La elección de asambleístas indígenas se realiza mediante competencia electoral y voto individual y el uso de normas y procedimientos propios se circunscribe a la selección de candidatos con pertenencia identitaria específica. La elaboración de cinco estatutos departamentales 
muestra un incremento de asambleístas indígenas en dos casos (Pando y Potosí) respecto a los comicios de 2010, pero no se registra alguna modificación sustantiva en las modalidades de elección. Los desafíos parecen referirse a un tópico distinto a la configuración de la representación política puesto que se trata de impulsar el funcionamiento de las asambleas departamentales con apego a la democracia intercultural entendida como democracia deliberativa, es decir con predominio de lógica argumentativa y no meramente reglas decisorias. Para ello es preciso evaluar la capacidad deliberativa de este órgano de gobierno analizando la presencia y conducta de los representantes indígenas para ver si inciden en la adopción de prácticas deliberativas por parte de otros representantes o su influencia se limita a la legitimidad del lazo representativo de los asambleístas indígenas sin efectos en el funcionamiento del órgano legislativo.

La democracia intercultural presenta, aparentemente, mayores avances en las flamantes autonomías indígenas por la adopción de reglas de democracia comunitaria para la elección de autoridades y representantes. El rasgo más destacado es el diseño de un sistema de gobierno con tres niveles donde sobresale una instancia máxima de carácter comunitario a la cual se subordinan los dos órganos convencionales (legislativo y ejecutivo). Esta instancia, denominada deliberativa, concentra el proceso decisional porque tiene atribuciones para definir la composición y desempeño de las instancias de gobierno. Esa instancia máxima de gobierno se conforma mediante normas y procedimientos propios, entre los que sobresale la representación directa de unidades menores a la cual se accede por rotación, es decir, la labor representativa no tiene carácter voluntario ni depende de un cuerpo electoral interpelado por candidatos. La ausencia de fronteras entre comunidades e instancias representativas no presenta problemas porque predomina la búsqueda de legitimidad en el lazo representativo. El desafío es evitar que esta falta de distinción, formalizada en los estatutos, atente contra la eficacia decisional de los órganos legislativo y ejecutivo y que no provoque una dualidad de funciones en determinadas situaciones. Otro desafío es definir su articulación a los niveles de gobierno departamental y nacional y, por ende, a la presencia de organizaciones políticas con tareas de mediación y competencia electoral. Esta es una tarea pendiente del ejercicio de las reglas formales de la democracia comunitaria; en todo caso, su concreción institucional a partir de 2015 permitirá saber si el camino de las autonomías indígenas se dirige a potenciar la democracia intercultural o simplemente a la configuración de espacios políticos autónomos pero sin incidencia decisiva en la competencia política en el nivel departamental y nacional, aunque su efecto político sea positivo en términos de legitimidad y representatividad. 